\title{
Abordagem clínica de pacientes com ataxia
}

\section{Clinical approach to ataxic patients}

Clécio de 0 Godeiro Jr. ${ }^{1}$, André Carvalho Felício ${ }^{1}$, Sônia Maria Azevedo Silva², Vanderci Borges², Henrique Ballalai Ferraz ${ }^{3}$

\section{RESUMO}

Ataxia é um sinal neurológico caracterizado pela incoordenação dos movimentos voluntários e é a principal manifestação de uma síndrome cerebelar. A classificação e o diagnóstico diferencial dos quadros de ataxia são complexos devido a grande variabilidade de etiologias e fenótipos clínicos. Revisamos as principais causas e ferramentas diagnósticas das síndromes atáxicas.

\section{Unitermos: Cerebelo, Ataxia espinocerebelar, Deficiência da Coordenação, Incoordenação.}

Citação: Godeiro Jr. CO, Felício AC, Silva SMA, Borges V, Ferraz HB. Abordagem Clínica de Pacientes com Ataxia. Rev Neurocienc 2007; 15(1):70-75.

\section{SUMMARY}

Ataxia is a neurological sign characterized by incoordination of voluntary movements and is the main manifestation of a cerebellar syndrome. Classification and differential diagnosis of ataxias are complex owing to the etiologic variability and clinical phenotypes. We review the main causes and diagnostic tools of the ataxic syndromes.

\section{Keywords: Cerebellum, Spinocerebellar Ataxia, Coordination impairment, Incoordination.}

Citation: Godeiro Jr. CO, Felício AC, Silva SMA, Borges V, Ferraz HB. Clinical Approach to Ataxic Patients. Rev Neurocienc 2007; 15(1):70-75.

\section{INTRODUÇÃO}

O termo ataxia significa, literalmente, falta de ordem, e é empregado desde os tempos de Hipócrates ou mesmo antes ${ }^{1}$. Do ponto de vista clínico, pode ser definido como um transtorno da atividade muscular coordenada, relacionado a alterações do cerebelo e de conexões aferentes e eferentes ${ }^{2}$. Além de alterações da marcha, este termo engloba outras anormalidades do movimento voluntário como: decomposição dos movimentos, dismetria e disdiadococinesia ${ }^{3}$.

O emprego deste termo para definir uma entidade clínica foi pela primeira vez utilizado por Friedreich em 18634. Neste caso, a ataxia era um sintoma mais proeminente de uma enfermidade persistente e progressiva.

A grande diversidade de doenças associadas a ataxia faz com que os clínicos recorram a um amplo arsenal de exames complementares. Entretanto, muitos pacientes com ataxia têm características clínicas tão específicas que permitem uma melhor seleção de tais exames. Com este texto, objetivamos apresentar uma proposta de investigação racional para estes pacientes.

Trabalho realizado no Departamento de Neurologia e Neurocirurgia, Setor de Transtornos do Movimento da Universidade Federal de São Paulo, São Paulo - SP, Brasil.

1. Neurologista, Pós-graduando do Setor de Transtornos do Movimento, UNIFESP.

2. Doutor em Neurologia, Médico assistente do Setor de Transtornos do Movimento, UNIFESP.

3. Doutor em Neurologia, Professor afiliado da disciplina de Neurologia e Chefe do Setor de Transtornos do Movimento, UNIFESP. 


\section{Abordagem Diagnóstica}

O primeiro aspecto a ser considerado na abordagem de um paciente com ataxia é a sua forma de início. Quadros agudos tornam obrigatória a exclusão de enfermidades focais do cerebelo, transtornos metabólicos e infecciosos ${ }^{5}$ (Tabela 1).

Neste aspecto, a realização de um exame de neuroimagem é extremamente útil. A ressonância magnética é preferível à tomografia computadorizada, pois obtém melhores imagens do cerebelo e do tronco encefálico6. Além desta, a realização de hemograma, glicemia, creatinina, perfil hepático e estudo liquórico, são importantes na investigação, uma vez que distúrbios metabólicos e infecções do sistema nervoso central podem estar associados a ataxia aguda.

A avaliação de um quadro de ataxia deve envolver uma ampla caracterização clínica dos sintomas associados, para assim permitir um melhor direcionamento na aplicação dos recursos propedêuticos. Os aspectos que devem ser valorizados estão descritos na Tabela 2.

Uma vez caracterizado o quadro como uma ataxia não aguda, uma nova gama de variáveis precisa ser avaliada. A primeira delas é saber se o quadro tem característica progressiva e/ou intermitente; ou se tem um comportamento estático ou não progressivo. Um exemplo de um quadro estático é o da encefalopatia anóxica-isquêmica.

As ataxias intermitentes caracterizam-se por episódios recorrentes de ataxia dentro de um contexto clínico específico. Há dois grupos específicos de enfermidades que cursam com este tipo de ataxia: doenças metabólicas e canalopatias. Na Tabela 3 apresentamos as principais ${ }^{1,7}$.

Outras doenças metabólicas que também cursam com ataxia intermitente são: doença de Hartnup, cetoacidúria de cadeia ramificada intermitente, defeitos no metabolismo do piruvato, deficiência de carboxilase e defeito de oxidação de ácidos graxos ${ }^{7}$.

Outra variável importante a ser avaliada é definir se o quadro é esporádico ou se está acompanhado de uma história familiar positiva. Diante disto, podemos classificar as ataxias como esporádicas /não-hereditárias ou hereditárias 8,9 (Tabela 4).

\section{Ataxias não-hereditárias}

A associação de disautonomia e sinais parkinsonianos com ataxia de início tardio é muito sugestiva de atrofia de múltiplos sistemas ${ }^{10}$. Embora apresente altera-

Tabela 1- Causas de Ataxias Agudas.

\begin{tabular}{|c|c|c|c|c|c|}
\hline \multicolumn{2}{|c|}{ Tumor } & \multicolumn{2}{|c|}{ Isquemia } & \multicolumn{2}{|c|}{ Intoxicação Exógena } \\
\hline \multicolumn{2}{|c|}{ Cerebelite Infecciosa } & $\begin{array}{r}\text { Hemor } \\
\text { Desmilinização: Es } \\
\text { Síndrome de N }\end{array}$ & $\begin{array}{l}\text { agia } \\
\text { clerose Múltipla } \\
\text { iller-Fischer }\end{array}$ & \multicolumn{2}{|c|}{ Encefalopatia de Wernicke } \\
\hline Sinais Cerebelares & Sinais Oculares & Sinais Extrapiramidais & Sinais Piramidais & Sinais de Neuropatia & Outros Sinais \\
\hline $\begin{array}{l}\text { Distúrbio da Marcha } \\
\text { Ataxia apendicular } \\
\text { Alteração da fala } \\
\text { Hipotonia }\end{array}$ & $\begin{array}{l}\text { Motricidade Ocular } \\
\text { Extrínseca: } \\
\text { Sacada } \\
\text { Perseguição } \\
\text { Nistagmo } \\
\text { Oftalmoplegia } \\
\text { "Bulging eyes" ou } \\
\text { Olhos esbugalhados } \\
\text { Atrofia Óptica } \\
\text { Degeneração Macular }\end{array}$ & $\begin{array}{c}\text { Tremor: } \\
\text { repouso } \\
\text { postural } \\
\text { ação } \\
\text { Parkinsonismo } \\
\text { Coréia } \\
\text { Distonia } \\
\text { Mioclonias } \\
\text { Mioquimias }\end{array}$ & $\begin{array}{l}\text { Reflexos tendíneos } \\
\text { vivos/exaltados } \\
\text { Sinal de Babinski } \\
\text { Espasticidade }\end{array}$ & $\begin{array}{c}\text { Arreflexia } \\
\text { Amiotrofia } \\
\text { Fasciculações } \\
\text { Alteração de Sensibilidade }\end{array}$ & $\begin{array}{c}\text { Demência } \\
\text { Distúrbio Psiqiátrico } \\
\text { Epilepsia } \\
\text { Distúrbio do Sono } \\
\text { Disautonomia }\end{array}$ \\
\hline
\end{tabular}


Tabela 3. Principais causas de Ataxia Intermitente.

\begin{tabular}{|c|c|c|c|}
\hline Doença & Defeito Genético-Bioquímico & Característica Clínica & Tipo de Herança \\
\hline Ataxia Episódica 1 & $\begin{array}{c}\text { Mutação do gene KCNA1 - canal de potássio } \\
\text { voltagem dependente }\end{array}$ & $\begin{array}{l}\text { Neuromiotomia } \\
\text { Mioquimia }\end{array}$ & $\begin{array}{l}\text { Autossômica Domi- } \\
\text { nante }\end{array}$ \\
\hline Ataxia Episódica 2 & $\begin{array}{c}\text { Mutação do gene CACNA1A - canal de cálcio } \\
\text { do tipo P/Q }\end{array}$ & $\begin{array}{c}\text { Vertigem, diplopia, nistagmo e náu- } \\
\text { sea } \\
\text { Migrânea hemiplégica } \\
\text { Associação com SCA }\end{array}$ & $\begin{array}{l}\text { Äutossômica Domi- } \\
\text { nante }\end{array}$ \\
\hline $\begin{array}{c}\text { Hiperamonemia } \\
\text { (Deficiência de enzimas do ciclo da } \\
\text { uréia) }\end{array}$ & Deficiência de Ornitina Transcarbamilase & $\begin{array}{l}\text { Retardo do desenvolvimento } \\
\text { Epilepsia } \\
\text { Movimentos involuntários } \\
\text { Disartria }\end{array}$ & $\begin{array}{l}\text { Autossômica Reces- } \\
\text { siva }\end{array}$ \\
\hline
\end{tabular}

Tabela 4. Classificação das ataxias progressivas de acordo com seu padrão de herança.

\begin{tabular}{cc}
\hline Ataxias não-hereditárias & Ataxias hereditárias \\
\hline Atrofia de Múltiplos Sistemas, forma cerebelar & Ataxias autossômicas recessivas \\
Degeneração Cerebelar Paraneoplásica & Ataxias autossômicas dominantes \\
Doença Priônica & Doença Mitocondrial \\
Doença Celíaca & Síndrome tremor/ataxia associada ao X-Frágil \\
Degeneração Cerebelar Alcoólica & \\
\hline
\end{tabular}

ções na ressonância magnética de crânio, como atrofia do putâmen e do cerebelo associada a hipossinal de putâmen na seqüência T26, seu diagnóstico não deve ser firmado até que outras causas sejam excluídas.

A maior parte das síndromes paraneoplásicas sintomáticas são raras, afetando cerca de 0,01\% dos pacientes com câncer ${ }^{11}$. A degeneração cerebelar paraneoplásica é causada pela formação de anticorpos contra estruturas do sistema nervoso central, particularmente os anticorpos anti-Hu e anti-Yo ${ }^{12}$. Uma vez que o transtorno neurológico pode anteceder o aparecimento do tumor em meses ou anos, este diagnóstico deve, sempre que possível, ser pesquisado em ataxias de início tardio, com o uso de marcadores tumorais e estudos de imagem de órgãos sólidos.

A doença de Creutzfeldt-Jakob, que é a mais comum das doenças priônicas afetando os humanos, caracteriza-se por deterioração neurológica subaguda, degeneração espongiforme da substância cinzenta, e acúmulo da proteína priônica PrPsc no cérebro ${ }^{13,14}$. A principal característica clínica desta enfermidade é um quadro demencial rapidamente progressivo associado a mioclonias. Entretanto, um grupo de pacientes com esta doença cursa com quadro predominante de ataxia com evolução lenta, sem as alterações características do eletroencefalograma que são os complexos periódicos de ondas agudas ${ }^{13}$. Nestes casos, dois instrumentos diagnósticos são úteis: a dosagem de proteína 14-3-3 no líquor e a ressonância magnética de crânio com difusão, a qual revela hipersinal nos núcleos da base e/ou córtex cerebral' ${ }^{15}$.

A doença celíaca é uma enteropatia induzida pelo glúten e suas manifestações neurológicas devem-se a um déficit vitamínico, particularmente de vitamina $\mathrm{E}$, e cursa com quadro de ataxia associada a arreflexia e liberação piramidal ${ }^{16}$. Alguns pacientes desenvolvem manifestações correspondentes com a síndrome de Ramsey-Hunt cursando com ataxia progressiva e mioclonias de ação ou estímulo-sensível ${ }^{17}$. O diagnóstico pode ser confirmado com a pesquisa de anticorpos antigliadina e antiendomisio, assim como com a demonstração de atrofia na biópsia da mucosa intestinal.

A degeneração cerebelar alcoólica é provavelmente a causa mais comum de ataxia crônica e parece envolver desnutrição, neurotoxicidade alcoólica e fatores individuais ${ }^{1}$. O questionamento sobre o alcoolismo deve ser sempre incluído no interrogatório de um paciente com ataxia. 


\section{Ataxias Autossômicas Recessivas}

O padrão de herança autossômica recessiva deve ser suspeitado quando vários indivíduos de uma mesma geração são afetados e seus genitores são saudáveis. Além disso, a presença de consangüinidade e início precoce são pistas importantes.

Este grupo de ataxias é heterogêneo e o diagnóstico depende da identificação de características clínicas associadas, o que permite um direcionamento no teste diagnóstico $0^{7,18}$

Apresentamos as principais características clínicas e o exame confirmatório de ataxias autossômicas recessivas $^{1,7,8,18}$ (Tabela 5).

\section{Ataxias Autossômicas Dominantes}

Existe uma grande dificuldade em se fazer a classificação nosológica neste grupo de ataxias devido a grande variabilidade fenotípica inter e intrafamilial ${ }^{19}$. A presença de ataxia em gerações subseqüentes de uma mesma família é um dado altamente sugestivo de herança autossômica dominante, principalmente se estiver associado ao início tardio (após 25 anos de idade) e se

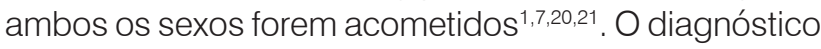
de certeza só pode ser firmado através da análise molecular do DNA dos pacientes acometidos ${ }^{7,9,21}$, apesar de vários grupos de pacientes com a mesma mutação apresentarem características fenotípicas em comum. Já foram descritos 25 tipos de ataxias espinocerebelares de herança autossômica dominantes (SCAs) e estudos para identificação de nova mutações estão em andamento ${ }^{9,21}$. No Brasil, as SCAs mais freqüentes são: a SCA3, ou doença de Machado-Joseph seguida das SCA10, SCA2, SCA7, SCA1 e SCA $6{ }^{22,23}$ (Tabela 6).

A Doença de Machado Joseph/SCA 3 foi originalmente descrita em pacientes norte-americanos originários das ilhas portuguesas dos Açores ${ }^{24}$. Há três tipos de expressão clínica ${ }^{1}$ :

- Tipo 1: início precoce e curso rápido, causando ataxia, oftlamoplegia, sinais piramidais e extrapiramidais;

- Tipo 2: é o tipo mais comum encontrado na populção brasileira ${ }^{25}$. Tem início na $4 a$ década de vida e cursa com ataxia e oftalmoplegia;

- Tipo 3: tem um início tardio e caracteriza-se pela presença de neuropatia.

A mutação responsável pela SCA-3 é uma expansão anormal de trinucleotídeos CAG no cromossomo 14q32.1, levando a codificação anormal do produto gênico ataxina- ${ }^{31}$. Quanto maior o número de repetições e associado a a herança paterna, maior a chance de um início precoce da enfermidade ${ }^{25}$. No Brasil, provavel- mente devido a miscigenação racial, a idade de início é mais precoce em relação a população portuguesa (34 versus 40,5 anos) $)^{25}$.

Se a pesquisa das alterações genéticas que ocorrem nas SCAs for negativa em um paciente com ataxia e herança autossômica dominante, devemos considerar as hipóteses de Atrofia Dentatorubral-Pálidoluysiana (DRPLA) e doença de Gerstmann-Sträussler-Scheinker.

A DRPLA foi originalmente descrita em 1946 e é causada por uma expansão de trinucleotídeos no cromossomo $^{12}$. Quando tem início precoce, o fenótipo dominante é o de ataxia e mioclonias, já quando o início é tardio, a coreoatetose, a demência e a psicose são os sintomas que predominam ${ }^{26,27}$. Não existe nenhum caso identificado de DRPLA no Brasil.

A doença de Gerstmann-Sträussler-Scheinker é uma doença priônica e se caracteriza por ataxia cerebelar de início insidioso e progressivo associada a demência, sinais bulbares e corticoespinhais ${ }^{28}$.

\section{Ataxias de herança ligada ao X}

Este tipo de herança é caracterizado pelo fato de a doença ser transmitida sem saltar gerações, assim como a herança autossômica dominante. Quando ocorre de forma recessiva os homens são afetados com a presença de um único gene. Já quando o padrão é dominante, as mulheres são mais afetadas que os homens. Apresentamos duas enfermidades que tem seu padrão de herança ligado ao $\mathrm{X}$ e podem cursar com ataxia: a síndrome de tremor/ataxia ligado ao X-Frágil e as doenças mitocondriais.

A síndrome do X Frágil é a causa hereditária mais comum de retardo mental e é causada por uma expansão de trinucleotídeos na região do gene FMR1 no cromossomo Xq27.3. Indivíduos com mais de 200 repetições desenvolvem o quadro clássico de retardo no desenvolvimento psicomotor. Por outro lado, aqueles com 50 a 200 repetições, ou seja, com a pré-mutação, desenvolvem um quadro caracterizado por ataxia cerebelar progressiva, parkinsonismo, tremor, disfunção autonômica e demência ${ }^{29,30}$. O início dos sintomas costuma ocorrer após os 50 anos de idade. Portanto, este diagnóstico deve ser incluído no diagnóstico diferencial de ataxias de início tardio, principalmente se há história familiar de retardo menta| 30,31 .

As mitocondriopatias são causadas por mutações esporádicas ou espontâneas no DNA mitocondrial e/ou nuclear. As enfermidades causadas por este processo causam as mais diferentes manifestações clínicas ${ }^{32}$. Apresentamos as principais síndromes mitocondriais que cursam com ataxia e suas características peculiares (Tabela 7). 
Tabela 5. Ataxias Autossômicas Recessivas

\begin{tabular}{|c|c|c|}
\hline Ataxia & Característica Clínica & Teste Diagnóstico \\
\hline Ataxia de Friedreich & $\begin{array}{l}\text { Arreflexia com sinal de Babinski. } \\
\text { Escoliose e pé cavo } \\
\text { Cardiomiopatia Hipertrófica }\end{array}$ & Estudo do gene X25/FRDA - Frataxina \\
\hline $\begin{array}{l}\text { Ataxia com deficiência isolada de Vi- } \\
\text { tamina } \mathrm{E}\end{array}$ & Fenótipo semelhante a ataxia de Friedreich, com distonia & Redução dos níveis séricos de Vitamina $\mathrm{E}$ \\
\hline Ataxia Telangiectasia & $\begin{array}{c}\text { Face impassiva e sialorréia } \\
\text { Telangiectasias } \\
\text { Deficiência Imunológica - pneumonias freqüentes }\end{array}$ & $\begin{array}{l}\text { Elevação da Alfa-Fetoproteína sérica } \\
\text { Baixos níveis de imunoglobulina } \\
\text { Cariótipo: translocação de cromossomos 7;14 } \\
\text { Radiossensibilidade de fibroblastos in vitro } \\
\text { Estudo do gene ATM }\end{array}$ \\
\hline Abetalipoproteinemia & Diarréia logo após nascimento & $\begin{array}{c}\text { Redução dos níveis de Vitamina E } \\
\text { Eletroforese Lipídica }\end{array}$ \\
\hline Doença de Refsum & $\begin{array}{c}\text { Neuropatia sensitivo-motora } \\
\text { Degeneração pigmentar da retina } \\
\text { Surdez } \\
\text { Ictiose }\end{array}$ & Diminuição ou ausência do Ácido fitânico \\
\hline Xantomatose Cerebrotendínea & $\begin{array}{l}\text { Xantomas tendinosos } \\
\text { Catarata }\end{array}$ & $\begin{array}{c}\text { Aumento dos níveis de Colestanol e colesterol } \\
\text { séricos }\end{array}$ \\
\hline Leucodistrofia Metacromática & $\begin{array}{c}\text { Retardo do desenvolvimento } \\
\text { Atrofia óptica } \\
\text { Espasticidade }\end{array}$ & Redução de Arilsulfatase sérica \\
\hline Leucodistrofia de células globóides & $\begin{array}{l}\text { Retardo do desenvolvimeto } \\
\text { Déficit visual } \\
\text { Espasticidade }\end{array}$ & $\begin{array}{l}\text { Redução da atividade da Beta-galactocerebrosi- } \\
\text { dase }\end{array}$ \\
\hline Lipofuccinose Ceróide Neuronal & $\begin{array}{l}\text { Déficit visual progressivo } \\
\text { Déficit cognitivo } \\
\text { Epilepsia }\end{array}$ & Análise Ultraestrutural de linfócitos e pele \\
\hline Gangliosidose GM2 & Manchas Vermelho-Cereja na retina & Deficiência de Hexoaminidase A e B \\
\hline Niemann-Pick C & Oftalmoplegia supranuclear vertical & $\begin{array}{l}\text { Biópsia de Medula Óssea } \\
\text { Diminuição da Esfingomielinase } \\
\text { Estudo do gene NPC1NPC2 }\end{array}$ \\
\hline
\end{tabular}

Tabela 6. Característica peculiar das principais SCAs encontradas no Brasil.

\begin{tabular}{|c|c|}
\hline Enfermidade & Característica Peculiar \\
\hline SCA1 & $\begin{array}{c}\text { Sinais corticoespinhais e bulbares } \\
\text { Neuropatia Periférica } \\
\text { Alteração da motricidade ocular extrínsica - sacadas }\end{array}$ \\
\hline SCA2 & $\begin{array}{l}\text { Sacadas lentas } \\
\text { Neuropatia periférica } \\
\text { Sinais extrapiramidais }\end{array}$ \\
\hline SCA3/ Doença de Machado-Joseph & $\begin{array}{l}\text { Alteração da motricidade ocular extrínsica - diplopia e sacadas } \\
\text { "Bulging Eyes" ou olhar esbugalhado } \\
\text { Sinais corticoespinhais } \\
\text { Sinais extrapiramidais } \\
\text { Neuropatia periférica }\end{array}$ \\
\hline SCA6 & $\begin{array}{c}\text { Ataxia "pura" } \\
\text { Alteração da motricidade ocular extrínsica }\end{array}$ \\
\hline $\begin{array}{l}\text { SCA7 } \\
\text { SCA10 }\end{array}$ & $\begin{array}{c}\text { Degeneração retiniana } \\
\text { Epilepsia* }\end{array}$ \\
\hline
\end{tabular}

\footnotetext{
* Nos casos descritos no Brasil por Teive et al23, não foi observada a presença de epilepsia.
} 
Tabela 7. Características peculiares das mitocondriopatias que cursam com ataxia

\begin{tabular}{|c|c|}
\hline Síndromes & Peculiaridade Clínica \\
\hline Kearn-Sayre & $\begin{array}{c}\text { Oftalmoparesia externa progressiva (OEP) } \\
\text { Retinite pigmentosa } \\
\text { Surdez } \\
\text { Disfunção cardíaca }\end{array}$ \\
\hline MELAS & $\begin{array}{l}\text { Episódios sugestivos de acidente vascular } \\
\text { cerebral } \\
\text { Epilepsia } \\
\text { Atrofia Optica } \\
\text { Surdez } \\
\text { Acidose Láctica }\end{array}$ \\
\hline MERRF & $\begin{array}{c}\text { Miopatia } \\
\text { Demência } \\
\text { Epilepsia Mioclônica } \\
\text { Surdez } \\
\text { OEP }\end{array}$ \\
\hline Leigh & $\begin{array}{c}\text { Retardo no desenvolvimento } \\
\text { Epilpsia } \\
\text { Sinais piramidais } \\
\text { Retinite pigmentosa } \\
\text { OEP }\end{array}$ \\
\hline NARP & $\begin{array}{c}\text { Polineuropatia sensitivo-motora } \\
\text { Retinite pigmentosa } \\
\text { Retardo mental } \\
\text { Epilepsia }\end{array}$ \\
\hline May-White & $\begin{array}{l}\text { Mioclonia } \\
\text { Surdez }\end{array}$ \\
\hline
\end{tabular}

\section{REFERÊNCIAS BIBLIOGRÁFICAS}

1. Klockgether T. Handbook of Ataxia Disorders. New York: Mercel Dekker 2000, 692p.

2. Brazis PW, Masdeu JC, Biller J. Localization in Clinical Neurology. 4th edition. Philadelphia: Lippincott Williams \& Williams, 2001, 598p.

3. Haerer AF. DeJong 's: The Neurological Examination. 5th edition. Philadelphia: Lippincott Williams \& Williams, 1992, 844p.

4. Friedreich N. Über degenerative Atrophie der spinalen Hintersträngen. Virchows Arch Pathol Anat Physio 1863; 22:1-26.

5. Massaquoi SG, Hallett M. Ataxia and other cerebellar syndromes. In: Jankovic $\mathrm{JJ}$, Tolosa E. Parkinson's Disease and Movement Disorders. 4th edition. Philadelphia: Lippincott Williams \& Williams, 2002, p393-408.

6. Wüller U, Klockgether T, Petersen D, Naegele T, Dichgans J. Magnetic Resonance imaging in hereditary and idiopathic ataxia. Neurology 1993; 43: 318-325

7. De Michelle G, Coppola G, Cocozza S, Filla A. A pathogenetic classification of hereditary ataxias: is the time ripe. J Neurol 2004; 251:913-922.

8. DiDonato S, Gallera C, Mariotti C. The Complex clinical and gentic classification of inherited ataxias II: autosomal recessive ataxias. Neurol Sci 2001; 22(3): 219-228.

9. Schöls L, Bauer P, Schimdt T, Schulte T, Riess O. Autosomal dominant cerebellar ataxias: clinical features, genetics, and pathogenesis. Lancet Neurol 2004; 3: 291-304.

10. Wenning GK, Colosimo C, Geser F, Poewe W. Multiple System Atrophy. Lancet Neurol 2004; 3: 93-103

11. Darnell RB, Posner JB. Paraneoplasic syndromes involving the nervous system. N Éngl J Med 2003; 349: 1543-1554.

12. Peterson K, Rosenblwa MK, Kotaraides H, Posner JB. Paraneoplasic cerebellar degeneration: A clinical analysis of 55 anti-Yo antibody positive patients. Neurology 1992; 42: 1931-1937.

13. Malluci G, Collinge J. Update on Creutzfeldt-Jakob disease. Curr Opin Neurol $2004 ; 17: 641-647$

14. Castellani RJ, Colucci M, Xie Z, Zou W, Li C, Parchi P, et al. Sensitivity of 14 3-3 protein test varies in subtypes of sporadic Creutzfeldt-Jakob disease. Neurology 2004; 63: 436-442.

15. Shiga Y, Miyazawa K, Sato S, Fukushima R, Shibuya S, Sato Y, et al. Diffusionweighted MRI abnormalities as an early diagnostic marker for CreutzfeldtJakob disease. Neurology 2004; 63: 443- 449.

16. Kinney HC, Burger PC. Hurwitz BJ. Degeneration of the central nervous system associated with celiac disease. J Neurol Sci 1982; 53: 9-13.

\section{CONSIDERAÇÕES FINAIS}

As formas esporádicas de ataxia devem ser diferenciadas das formas hereditárias. Embora, atualmente as técnicas de biologia molecular nos propiciem o diagnóstico preciso, o início da investigação de um quadro atáxico reside em uma anamnese apropriada, com intensa exploração da história familiar, associada a um exame físico completo e minucioso. Com estes dados o direcionamento para investigação com exames complementares será objetivo e menos dispendioso.

17. Chinnerey PF, Reading PJ, Milne D, Gardner-Medwin D, Turnbull DM. CSF anti-gliadin antibodies and the Ramsey-Hunt syndrome. Neurology 1997 49: 1131-1133

18. Filla A, De Michelle G, Barbieri F Campanella G. Early onset hereditary ataxias of unknown origin etiology: review of a personal series. Acta Neurol (Napoli) 1992; 14(4-6): 420-430.

19. Arruda WO, Teive HAG. Ataxias cerebelares hereditárias: do martelo ao gen Arq Neuropsiquiatr 1997; 55(3B): 666-676

20. Harding AE. Classification of the Hereditary Ataxias and Paraplegias. Lancet 1983; 1: 1151- 1155

21. Manto MU. The wide spectrum of spinocerebelar ataxias (SCAs). The Cerebellum 2005; 4: 2-6.

22. Jardim LB, Silveira I, Pereira ML. A survey of spinocerebellar ataxia in South Brazil - 66 new cases with Machado-Joseph disease, SCA7, or unidentified disease causing mutations. J Neurol 2001; 248: 870-876.

23. Teive HAG, Roa BB, Raskin S. Clinical Phenotype of Brazilian families with Spinocerebellar Ataxia 10. Neurology 2004; 63: 1509-1512.

24. Coutinho P. Andrade C. Autosomal dominant system degeneration in Portuguese families of the Azores Islands. Neurology 1978; 28: 248-250.

25. Jardim LB, Pereira ML, Ferro A. Machado-Joseph disease in South Brazil - clinical ad molecular characterization of Kindreds. Acta neurol Scand 2001; 104: 224-231.

26. Titica J, Van Bogaert L. Heredo-degenerative hemiballismus. Brain 1946; 69:251-262.

27. Nagafuchi S, Yanagisawa H. Sato K. Dentatorubral and pallidoluysian atrophy expansion of the unstable CAG trinucleotide on chromosome 12p. Nat Genet 1994; 6: 14-18.

28. Masters CL, Gaujdusek DC, Gibbs CJ. Creutzfeldt-Jakob disease virus isolations from the Gerstmann-Straussler syndrome. Brain 1981; 104: 509.

29. Hagerman RJ, Leehey M, Heinrichs W, Tassone F, Wilson R, Hills J, et al Intention tremor, parkinsonism, and generalized brain atrophy in male carriers of fragile X. Neurology 2001; 57: 127-130

30. Baba Y, Uitti RJ. Fragile X-associated tremor/ataxia syndrome and movement disorders. Curr Opin Neurol 2005; 18: 393-398.

31. Tan EK, Zhao Y, Puong KY, Law HY, Chan LL, Yew K, et al. Fragile X premutation alleles in SCA, ET, and parkinsonism in an Asian Cohort. Neurology 2004; 63:362-363.

32. Finsterer J. Mitochondriopathies. Eur J Neurol 2004; 11: 163-186. 